\title{
The clinical association between Periodontitis and COVID-19
}

\author{
Shipra Gupta ${ }^{1}$ (D) $\cdot$ Ritin Mohindra ${ }^{2} \cdot$ Mohita Singla $^{1} \cdot$ Sagar Khera $^{2} \cdot$ Vaibhav Sahni $^{3} \cdot$ Poonam Kanta $^{4}$. \\ Roop Kishor Soni ${ }^{2} \cdot$ Amit Kumar $^{1} \cdot$ Krishan Gauba $^{1} \cdot$ Kapil Goyal $^{4} \cdot$ Mini P. Singh $^{4} \cdot$ Arnab Ghosh $^{4} \cdot$ Kamal Kajal $^{5}$. \\ Varun Mahajan ${ }^{5} \cdot$ Ashish Bhalla $^{2} \cdot$ Timo Sorsa $^{6,7} \cdot$ Ismo Räisänen $^{6}$
}

Received: 28 May 2021 / Accepted: 27 July 2021 / Published online: 27 August 2021

(C) The Author(s), under exclusive licence to Springer-Verlag GmbH Germany, part of Springer Nature 2021

\begin{abstract}
Objectives The study aimed to clinically assess the association between periodontitis and COVID-19-related outcomes. Material and methods Data pertaining to patient demographics, medical history, blood parameters, periodontal clinical examination and aMMP-8 point-of-care diagnostics (both site-level and patient-level) was recorded for eighty-two COVID-19positive patients. COVID-19-related outcomes such as COVID-19 pneumonia, death/survival, types of hospital admission and need of assisted ventilation were also assessed.

Results Males were predominantly afflicted with COVID-19, with advanced age exhibiting a greater association with the presence of periodontitis. Higher severity of periodontitis led to 7.45 odds of requiring assisted ventilation, 36.52 odds of hospital admission, 14.58 odds of being deceased and 4.42 odds of COVID-19-related pneumonia. The aMMP- 8 mouthrinse kit was slightly more sensitive but less specific than aMMP-8 site-specific tests.

Conclusions Based on the findings of the present study, periodontitis seems to be related to poorer COVID-19-related outcomes. However, within the constraints of this work, a direct causality may not be established. Periodontitis, by means of skewing the systemic condition for a number of comorbidities, may eventually influence COVID-19 outcomes in an indirect manner.

Clinical relevance The study is the first to clinically, and by means of a validated point-of-care diagnostic methodology, assess the association between periodontal health and COVID-19-related outcomes. Assessment of the periodontal status of individuals can aid in the identification of risk groups during the pandemic along with reinforcing the need to maintain oral hygiene and seeking periodontal care.
\end{abstract}

Keywords SARS-CoV-2 COVID-19 Periodontitis $\cdot$ Oral health $\cdot$ Oral hygiene $\cdot$ Matrix metalloproteinases $\cdot$ Prevention $\cdot$ Comorbidities $\cdot$ Ventilation $\cdot$ Diagnostics $\cdot$ Periodontics $\cdot$ Periodontal $\cdot$ Dental

Shipra Gupta and Ritin Mohindra contributed equally to this work.

Shipra Gupta

shipra1472@gmail.com

1 Oral Health Sciences Centre, Post Graduate Institute of Medical Education \& Research (PGIMER), Chandigarh, India

2 Department of Internal Medicine, PGIMER, Chandigarh, India

3 Panjab University, Chandigarh, India

4 Department of Virology, PGIMER, Chandigarh, India

5 Department of Anaesthesia \& Intensive Care, PGIMER, Chandigarh, India

6 Department of Oral and Maxillofacial Diseases, University of Helsinki and Helsinki University Hospital, Helsinki, Finland

7 Department of Oral Diseases, Karolinska Institutet, Stockholm, Sweden

\section{Introduction}

The COVID-19 pandemic has presented a conundrum like never before in terms of understanding its pathophysiology. With no cure in sight, it remains a significant aspect of research to identify and delineate factors which may alter the course of the disease in order to aid in its understanding and subsequent management. This would continue to assume importance even with the advent of anti-COVID-19 vaccinations.

Periodontal disease is considered a pandemic in its own right, with the reported case load far exceeding that of COVID-19. The disease process, though being non-fatal and chronic in nature, plays a crucial role not only in determining oral health but also as a significant contributor to the pathophysiology of a number of systemic conditions. There is sufficient evidence in literature to warrant an association between the presence of periodontal disease and the development and 
course of respiratory illnesses [1]. These mechanistic links range from a direct aspiration of these pathogens into the lungs to more indirect mechanisms wherein virulence factors and enzymes released by periodontopathogens may modify mucosal surfaces to make them more amenable to colonisation, destroy bacterial salivary pellicle to inhibit their subsequent clearance or modify the respiratory epithelium via cytokines in order to promote infection [2].

Indeed several hypotheses have pointed towards the possibility of a link between periodontal disease and COVID-19 [3, 4]. Detection of severe acute respiratory syndrome coronavirus 2 (SARS-CoV-2) in the gingival crevicular fluid (GCF) further gives credence to this theory and introduces the possibility of another point of entry [5].

SARS-CoV has been known to cause alterations in lung tissue due to numerous pathways, of which one involves mediation via matrix metalloproteinases (MMPs) [6]. MMPs cause extracellular matrix degradation along with mediating lung tissue remodelling; these factors eventually contribute to enhanced vascular permeability as well as damage to the endothelium. Acute respiratory distress syndrome (ARDS) management involves the utilisation of mechanical ventilation which can further lead to lung injury via ventilation-induced MMP-8 expression $[6,7]$. Indeed, the eventual mortality of patients has been related to the expression of MMP-8, MMP9, MMP-2 and TIMP-1, as is observed in early sepsis. MMPs have also been implicated in facilitating early virus entry into cells [8].

Over time, it has also become clear that proteinases, particularly collagenase- 2 , responsible for causing matrix degradation are chiefly obtained from polymorphonuclear leukocytes (PMNs) found in the diseased periodontium [9, 10]. Upon release from PMNs, the latent forms of these MMPs convert to their activated states by means of their interaction with reactive oxygen species or by proteolytic cleavage. Indeed, PMNderived MMP-8 activity is elevated in the gingival tissue, GCF, and saliva of patients suffering from periodontitis [9].

The active MMP-8 point-of-care (aMMP-8 POC) test has been validated in various countries in both adolescent and adult populations as a means to define active and inactive sites of periodontal disease, assess prognosis and evaluate patients in the treatment and maintenance phases [11-14]. This particular point-of-care testing methodology possesses a sensitivity of $76-83 \%$ and specificity of $96 \%$ with results being returned within 5-7 minutes $[15,16]$.

A number of hypothetical models have been put forth to assess the possibility of a link between oral hygiene and/or periodontal disease and the COVID-19 disease process [3, 17, 18]. A few studies based on patient data have also been published, which generally point towards periodontal disease as a determinant of poorer COVID-19-related outcomes [19, 20]. These studies, however, suffer from the fatal flaw of simply utilising previously collected patient data or few self-reported oral health indicators and correlating it to their current COVID-19 disease process.

In the present study, the authors went several steps further and performed real-time clinical assessments of patients suffering from COVID-19 along with utilising a validated aMMP-8 point-of-care bedside diagnostic test kit in order to evaluate the presence of active periodontal disease.

It is the belief of the authors that this is the first such study to perform clinical and diagnostic assessments in COVID-19 patients in the manner described. The aim of this study was to assess the association of periodontal health on the complications of COVID-19.

\section{Methods}

The cross-sectional analytical study was carried out by the Unit of Periodontics, Oral Health Sciences Centre, in collaboration with the Department of Internal Medicine, Department of Anaesthesia \& Department of Virology, Postgraduate Institute of Medical Education and Research, Chandigarh, India. The study was performed according to the Declaration of Helsinki. Due approval was taken from the Postgraduate Institute of Medical Education and Research, Chandigarh Institutional Ethics Committee (INT/IEC/2021/SPL-636). The present study conforms to STROBE guidelines. Eightytwo patients reporting to the communicable diseases ward or admitted in the hospital between 15.January-2021 and 20. February-2021 were recruited into the study after their COVID-19 status was confirmed by nasopharyngeal swab (NPS) testing. A patient information sheet was given to all the patients, and written informed consent was obtained from all the subjects. Pregnant ladies, patients less than 18 years old and those unwilling or not in a position to give written informed consent were excluded from the study. The sample size was based on convenient sampling owing to the fact that the study setting was a dedicated COVID-19 centre and the close proximity required on part of the healthcare worker (HCW) with a potentially infectious patient to conduct intraoral examination and aMMP-8 analysis. However, as no sample size estimation was done a priori, a post hoc power analysis was performed to validate the same. Demographic data was recorded, and chairside tests run for evaluating the expression of aMMP-8 at the site with maximum periodontal breakdown as well as via a mouthrinse-based kit for general disease activity.

\section{Training and calibration}

For training and calibration of the examiners, a COVID-19negative cohort of 10 subjects was enrolled from the Out Patient Department of the Oral Health Sciences Centre. It involved comprehensive periodontal clinical examination by 
a single examiner (SG) and running of chairside tests for evaluating expression of aMMP-8 by another examiner (MS). Interexaminer reliability was found to be 0.91 using Cohen kappa for categorical variable and 0.93 using intraclass correlation coefficient for continuous variable.

\section{Patient-related characteristics}

\section{Covariates}

Covariates like age, sex, smoking habits and other COVID19-related comorbidities/risk factors such as diabetes, hypertension, pulmonary disease, chronic kidney disease, cancer, coronary artery disease, obesity and any other comorbidities were recorded.

Blood parameters relevant to the disease progression such as C-reactive protein (CRP), D-dimer, platelet count, ferritin, glycosylated haemoglobin (HbAlc), haemoglobin (Hb), vitamin D3, neutrophil/lymphocyte ratio (N/L), troponin, procalcitonin and $\mathrm{N}$-terminal-pro-brain natriuretic peptide (NT-proBNP) were recorded. These parameters were noted from the patients' records, if available. Hence, the number of samples varied in each parameter.

\section{Periodontal clinical examination}

Periodontal clinical examination was conducted by a single calibrated examiner (SG) using a $10-\mathrm{mm}$ round-tip manual Williams's periodontal probe. All permanent teeth, excluding the third molars, were examined at six sites per tooth (distobuccal, mid-buccal, mesio-buccal, disto-palatal, mid-palatal, mesio-palatal). Gingival recession (GR), gingival marginal level (GML), periodontal probing depth (PPD), bleeding on probing (BOP) and number of teeth present/missing/carious were recorded. Clinical attachment loss (CAL) was calculated. Patients were categorised into periodontally healthy, gingivitis and stage I-IV periodontitis, as per the new classification of periodontitis as described by Chapple et al. (2018), Trombelli et al. (2018) and Tonetti et al. (2018), based on their clinical examination alone, as conducting intra-oral radiographs for COVID-19-positive patients was not feasible [21-23].

\section{Sample collection and qualitative analysis for aMMP-8 PoC mouthrinse- and site-specific kits}

These tests were conducted by a second periodontist (MS) a priori unaware of the clinical examination results. aMMP-8 chairside lateral flow mouthrinse immunoassay test (PerioSafe, Dentognostics GmbH, Solingen, Germany) and aMMP-8 chairside lateral flow site-specific immunoassay test (ImplantSafe, Dentognostics GmbH, Jena, Germany) were run step by step according to the manufacturer's instructions as described in literature [11-14]. The colour changes due to immunoreactions were read after exactly $5 \mathrm{~min}$. In both cases, a single blue line indicated aMMP- 8 levels less than $20 \mathrm{ng} / \mathrm{ml}$ (negative; no risk), whereas two blue lines were representative of aMMP-8 levels more than $20 \mathrm{ng} / \mathrm{ml}$ (positive; increased risk), indicating active periodontal disease.

\section{Outcome variables}

COVID-19-related complications such as presence of COVID-19 pneumonia, death due to COVID-19, type of hospital admission and need of assisted ventilation were also assessed. Patients requiring oxygen via high-flow nasal cannula (HFNC), non-invasive ventilation (NIV) or through intubation and ventilator were categorised as patients requiring assisted ventilation, whereas those able to maintain their status quo on room air were categorised as patients not requiring assisted ventilation. Admissions were categorised into those isolated at home and those admitted in the hospital either in the wards or in the ICU as per their disease severity and treatment requirements. An attempt was made to evaluate the presence of active periodontal disease using a validated aMMP- 8 point-of-care bedside diagnostic test kit.

\section{Statistical analysis}

Descriptive and inferential statistical analyses have been carried out in the present study. The results were analysed by using IBM SPSS Statistics for Windows, Version 25.0. Armonk, NY: IBM Corp. Results for continuous measurements were presented as mean $\pm \mathrm{SD}$ (Min-Max) and those for categorical as frequency (Percentage). Normality of the data was assessed using Shapiro Wilk test/KolmogorovSmirnov test. Bivariate associations were examined using Fischer exact test/chi-square test. Kruskal-Wallis test was used to compare the variables at different levels of periodontal disease. Mann-Whitney $U$ test/Kruskal-Wallis test was also used to compare within the group. Logistic regressions were applied to obtain odds ratio with $95 \%$ confidence interval wherever possible. Since no sample size calculation was undertaken a priori, a post hoc power analysis was calculated from clinical.com (http://clincalc.com/stats/Power.aspx) using primary endpoint as dichotomous. A maximum power of 98 . 9\% was achieved between periodontal status of the patient and requirement of assisted ventilation.

\section{Results}

\section{COVID-19-positive cohort characteristics}

Table 1 presents the association of various parameters with stages of periodontitis. Forty-eight male patients and thirty- 
Table 1 Association of patient-related data with stages of periodontitis

\begin{tabular}{|c|c|c|c|c|c|c|c|c|}
\hline Parameters & & $\begin{array}{c}\text { Periodontally } \\
\text { healthy } \\
(n=27) \\
(\%)\end{array}$ & $\begin{array}{l}\text { Gingivitis } \\
\quad(n=21) \\
(\%)\end{array}$ & $\begin{array}{l}\text { Stage I } \\
\quad \text { periodontitis } \\
\quad(n=3)(\%)\end{array}$ & $\begin{array}{l}\text { Stage II } \\
\text { periodontitis } \\
(n=2)(\%)\end{array}$ & $\begin{array}{l}\text { Stage III } \\
\text { periodontitis } \\
(n=17)(\%)\end{array}$ & $\begin{array}{l}\text { Stage IV } \\
\quad \text { periodontitis } \\
(n=12)(\%)\end{array}$ & $p$ value \\
\hline Age (in years) & Mean \pm SD & $34.44 \pm 11.06$ & $\begin{array}{c}37.71 \pm \\
10.0\end{array}$ & $52.33 \pm 16.25$ & $44.00 \pm 18.38$ & $62.94 \pm 12.76$ & $61.58 \pm 9.07$ & $0.001 *$ \\
\hline Sex & $\begin{array}{l}\text { Male } \\
\text { Female }\end{array}$ & $\begin{array}{l}18(22) \\
9(11)\end{array}$ & $\begin{array}{l}11(13.4) \\
10(12.2)\end{array}$ & $\begin{array}{l}3(3.7) \\
0(0.0)\end{array}$ & $\begin{array}{l}1(1.2) \\
1(1.2)\end{array}$ & $\begin{array}{l}10(12.2) \\
7(8.5)\end{array}$ & $\begin{array}{l}5(6.1) \\
7(8.5)\end{array}$ & 0.486 \\
\hline $\begin{array}{l}\text { COVID-19 } \\
\text { symptoms }\end{array}$ & $\begin{array}{l}\text { Symptomatic } \\
\text { Asymptomatic }\end{array}$ & $\begin{array}{l}18(22) \\
9(11)\end{array}$ & $\begin{array}{l}16(19.5) \\
5(6.1)\end{array}$ & $\begin{array}{l}2(2.4) \\
1(1.2)\end{array}$ & $\begin{array}{l}0(0.0) \\
2(2.4)\end{array}$ & $\begin{array}{l}8(9.8) \\
9(11)\end{array}$ & $\begin{array}{l}7(8.5) \\
5(6.1)\end{array}$ & 0.219 \\
\hline $\begin{array}{l}\text { CT chest } \\
\text { (ground-glass } \\
\text { opacities) }\end{array}$ & $\begin{array}{l}\text { Present } \\
\text { Absent }\end{array}$ & $\begin{array}{l}3(3.7) \\
24(29.3)\end{array}$ & $\begin{array}{l}3(3.7) \\
18(22)\end{array}$ & $\begin{array}{l}1(1.2) \\
2(2.4)\end{array}$ & $\begin{array}{l}0(0.0) \\
2(2.4)\end{array}$ & $\begin{array}{l}5(6.1) \\
12(14.6)\end{array}$ & $\begin{array}{l}2(2.4) \\
10(12.2)\end{array}$ & 0.554 \\
\hline Comorbidities & $\begin{array}{l}\text { Present } \\
\text { Absent }\end{array}$ & $\begin{array}{l}18(22) \\
9(11)\end{array}$ & $\begin{array}{l}14(17.1) \\
7(8.5)\end{array}$ & $\begin{array}{l}1(1.2) \\
2(2.4)\end{array}$ & $\begin{array}{l}0(0.0) \\
2(2.4)\end{array}$ & $\begin{array}{l}7(8.5) \\
10(12.2)\end{array}$ & $\begin{array}{l}3(3.7) \\
9(11)\end{array}$ & 0.431 \\
\hline $\begin{array}{l}\text { Type of } \\
\text { comorbidity }\end{array}$ & $\begin{array}{l}\text { Diabetes } \\
\text { mellitus }\end{array}$ & $3(3.7)$ & $0(0.0)$ & $2(2.4)$ & $0(0.0)$ & $5(6.1)$ & $4(4.9)$ & $0.006^{*}$ \\
\hline & $\begin{array}{l}\text { Hypertension } \\
\text { Chronic kidney } \\
\text { disease }\end{array}$ & $\begin{array}{l}6(7.3) \\
1(1.2)\end{array}$ & $\begin{array}{l}4(4.9) \\
2(2.4)\end{array}$ & $\begin{array}{l}2(2.4) \\
2(2.4)\end{array}$ & $\begin{array}{l}0(0.0) \\
0(0.0)\end{array}$ & $\begin{array}{l}8(9.8) \\
3(3.7)\end{array}$ & $\begin{array}{l}5(6.1) \\
2(2.4)\end{array}$ & $\begin{array}{l}0.163 \\
0.075\end{array}$ \\
\hline & $\begin{array}{l}\text { Cardiovascular } \\
\text { diseases }\end{array}$ & $0(0.0)$ & $1(1.2)$ & $1(1.2)$ & $1(1.2)$ & $2(2.4)$ & $5(6.1)$ & $0.001 *$ \\
\hline & $\begin{array}{l}\text { Pulmonary } \\
\text { disease }\end{array}$ & $3(3.7)$ & $1(1.2)$ & $1(1.2)$ & $1(1.2)$ & $2(2.4)$ & $0(0.0)$ & 0.158 \\
\hline & Cancer & $0(0.0)$ & $1(1.2)$ & $0(0.0)$ & $1(1.2)$ & $4(4.9)$ & $1(1.2)$ & $0.023 *$ \\
\hline & Obesity & $0(0.0)$ & $0(0.0)$ & $0(0.0)$ & 0 & $1(1.2)$ & $1(1.2)$ & 0.241 \\
\hline & $\begin{array}{l}\text { Any other } \\
\text { comorbidity }\end{array}$ & $3(3.7)$ & $5(6.1)$ & $0(0.0)$ & $1(1.2)$ & $5(6.1)$ & $3(3.7)$ & 0.431 \\
\hline $\begin{array}{l}\text { Hospital } \\
\text { admission }\end{array}$ & $\begin{array}{l}\text { Required } \\
\text { Not required }\end{array}$ & $\begin{array}{l}11(13.4) \\
16(19.5)\end{array}$ & $\begin{array}{l}9(11.0) \\
12(14.6)\end{array}$ & $\begin{array}{l}3(3.7) \\
0(0.0)\end{array}$ & $\begin{array}{l}2(2.4) \\
0(0.0)\end{array}$ & $\begin{array}{l}17(20.7) \\
0(0.0)\end{array}$ & $\begin{array}{l}11(13.4) \\
1(1.2\end{array}$ & $0.001 *$ \\
\hline $\begin{array}{l}\text { Oxygen } \\
\quad \text { requirement }\end{array}$ & $\begin{array}{l}\text { Required } \\
\text { Not required }\end{array}$ & $\begin{array}{l}3(3.7) \\
24(29.3)\end{array}$ & $\begin{array}{l}5(6.1) \\
16(19.5)\end{array}$ & $\begin{array}{l}2(2.4) \\
1(1.2)\end{array}$ & $\begin{array}{l}0(0.0) \\
2(2.4)\end{array}$ & $\begin{array}{l}14(17.1) \\
3(3.7)\end{array}$ & $\begin{array}{l}6(7.3) \\
6(7.3)\end{array}$ & $0.001 *$ \\
\hline $\begin{array}{l}\text { COVID-19 } \\
\text { pneumonia }\end{array}$ & $\begin{array}{l}\text { Present } \\
\text { Absent }\end{array}$ & $\begin{array}{l}3(3.7) \\
24(29.3)\end{array}$ & $\begin{array}{l}4(4.9) \\
17(20.7)\end{array}$ & $\begin{array}{l}1(1.2) \\
2(2.4)\end{array}$ & $\begin{array}{l}0 \\
2(2.4)\end{array}$ & $\begin{array}{l}9(11.0) \\
8(9.8)\end{array}$ & $\begin{array}{l}5(6.1) \\
7(8.5)\end{array}$ & $0.025 *$ \\
\hline Survival & $\begin{array}{l}\text { Deceased } \\
\text { Survived }\end{array}$ & $\begin{array}{l}0 \\
27(32.9)\end{array}$ & $\begin{array}{l}1(1.2) \\
20(24.4)\end{array}$ & $\begin{array}{l}0 \\
3(3.7)\end{array}$ & $\begin{array}{l}0 \\
2(2.4)\end{array}$ & $\begin{array}{l}6(7.3) \\
11(13.4)\end{array}$ & $\begin{array}{l}1(1.2) \\
11(13.4)\end{array}$ & $0.009^{*}$ \\
\hline $\begin{array}{l}\text { Bleeding on } \\
\text { probing }\end{array}$ & $\begin{array}{l}\text { Present } \\
\text { Absent }\end{array}$ & $\begin{array}{l}0 \\
27(35.5)\end{array}$ & $\begin{array}{l}20(26.3) \\
1(1.3)\end{array}$ & $\begin{array}{l}3(3.9) \\
0\end{array}$ & $\begin{array}{l}2(2.6) \\
0\end{array}$ & $\begin{array}{l}11(14.5) \\
3(3.9)\end{array}$ & $\begin{array}{l}4(5.3) \\
5(6.6)\end{array}$ & $0.001 *$ \\
\hline
\end{tabular}

*Statistically significant $(p<0.05)$

four female patients were enrolled in the study. Age has been shown to be associated with periodontitis in literature. The present study results also exhibited an overall increase in age distribution with increasing stages of periodontitis in COVID19 patients. Fifty-one patients had typical symptoms of COVID-19, whereas thirty-one were asymptomatic on presentation. Presence or severity of periodontal diseases was not found to be associated with gender or presence/ absence of COVID-19 symptoms. Of the patients, $52.43 \%$ presented with one or more comorbidities. A statistically significant association was observed for diabetes mellitus, cardiovascular diseases and cancer. Predictors of COVID19-related outcomes such as hospital admission, requirement of assisted ventilation, COVID-19 pneumonia and eventual survival were observed to increase with a concomitant rise in the stage of periodontitis. Particularly, patients with a higher stage of periodontitis underwent ICU admission as opposed to those with a healthy periodontium or gingival disease who were found to be under home isolation or ward admission.

Likewise, requirement of assisted ventilation was more amongst patients with stage III and IV periodontitis. Twenty-two patients presented with COVID-19 pneumonia and fourteen had ground-glass opacities on CT chest. Majority of the patients survived and 9.7\% $(n=8)$ of the patients succumbed. These patients had a greater severity of periodontitis. One of the eight deceased patients had diabetes along with hypertension. Five of the deceased had other comorbidities like hypertension, CKD, history of $\mathrm{CAD}$ and acute necrotising pancreatitis. Bleeding on probing was commensurate with the stage of periodontal disease. 


\section{Blood parameters}

Tables 2, 3 and 4 report the associations between the periodontal status and blood parameters recorded at the time of examination. Bleeding on probing was not associated with any recorded blood parameter. Gingival recession and number of teeth missing due to periodontal reasons were associated with D-dimer and troponin values. Probing depth was significantly associated with $\mathrm{HbA1c}$, CRP, Ddimer and ferritin levels. Higher CAL was associated with elevated levels of CRP, D-dimer, pro-BNP, troponin and procalcitonin. Subjects with more severe forms of periodontitis had higher levels of D-dimer, pro-BNP and troponin.

\section{Association of periodontal and blood parameters with COVID-19 complications}

Table 5 presents the association between selected periodontal parameters and COVID-19 complications, in terms of requirement of assisted ventilation, hospital admission, presentation of COVID-19 pneumonia and survival.

Patients with bleeding on probing had 4.14 odds of requiring assisted ventilation, 3.18 odds for hospital admission and 3.63 odds of suffering from COVID-19 pneumonia. Probing depth, gingival recession and CAL were significantly associated with all the included complications of COVID-19. Increasing probing depth, CAL and presence of gingival recession in these patients put them at increased odds for these complications. Patients with gingival recession required assisted ventilation $(\mathrm{OR}=$ $8.22)$, had less chances of survival $(\mathrm{OR}=14.07)$, and 6.50 odds of COVID-19 pneumonia. However, missing teeth was only associated with increased odds of hospital admission $(\mathrm{OR}=12.52)$. Also, it was found that deceased patients had significantly higher mean probing depth, gingival recession and CAL compared to the survivors. Periodontal status was associated with all the included complications of COVID-19 in the present study. Higher severity of periodontitis led to 7.45 odds of requiring assisted ventilation, 36.52 odds of hospital admission, 14.58 odds of death and 4.42 odds of COVID-19 pneumonia.

Table 6 presents the association of COVID-19 complications and blood parameters recorded at the time of examination. Subjects requiring admission in hospital had significantly elevated levels of HbA1c, CRP, D-dimer, ferritin, N/L ratio, haemoglobin, pro-BNP, troponin and procalcitonin. Survival was found to be associated with elevated N/L ratio and platelet count, whereas subjects with higher levels of HbAlc, CRP, D-dimer, ferritin and procalcitonin required assisted ventilation.
aMMP-8 mouthrinse tests and aMMP-8 site specific tests

aMMP-8 mouthrinse kit was positive in $38.1 \%$, and aMMP-8 site-specific kit was positive in $33.3 \%$ of patients with periodontal disease. However, the kits also tested positive for $21.1 \%$ (mouthrinse kit) and $13.9 \%$ (site specific kit) in periodontally healthy subjects (Table 7).

\section{Discussion}

The findings of the present study establish an association between periodontal disease and COVID-19-related outcomes.

The results are in concordance with a study conducted by Marouf et al. (2021) who found a significant association to exist between periodontal disease and COVID-19-related outcomes [20]. This study utilised patient records available to predict periodontal outcome measures as risk factors for COVID-19 prognosis. However, no clinical assessment of their periodontal status at the time of suffering from the COVID-19 infection was made and hence patients with previous bone loss, but no active disease at the time of the study, might have been grouped along with those experiencing active disease. In our study, we not only conducted a real-time clinical examination of all the patients involved but also ran the aMMP-8 PoC chairside kits to determine the current activity of periodontal disease in the cohort. The current study, hence, makes the important distinction of assessing active periodontal disease and its relation to COVID-19-related outcomes.

The failure to maintain adequate ventilation has been touted as a significant marker of worsening COVID-19related outcomes. Indeed, hypoxemia has been observed to have been independently associated with in-hospital mortality [24]. In the present study, the authors found a significant association between bleeding on probing, increased periodontal probing depth, the presence of gingival recession, clinical attachment loss and oxygen requirement in COVID-19 patients. By this extension then, it would seem logical to conclude that poorer periodontal disease outcome measures might imply a worse COVID-19-related prognosis. Compromised periodontal outcome measures correlated significantly with the event of death in this patient population. Based on this finding it would thus be justified to state that patients with periodontal disease seemed to have a poorer chance of survival when compared to those without this ailment.

It is generally regarded that patients necessitating admission had taken or were expected to take a turn for the worse in terms of their prognosis. A significant rate of mortality has been demonstrated in patients hospitalised as a result of COVID-19 [25].

Compromised periodontal outcome measures correlated significantly with the event of hospital admissions; i.e. 


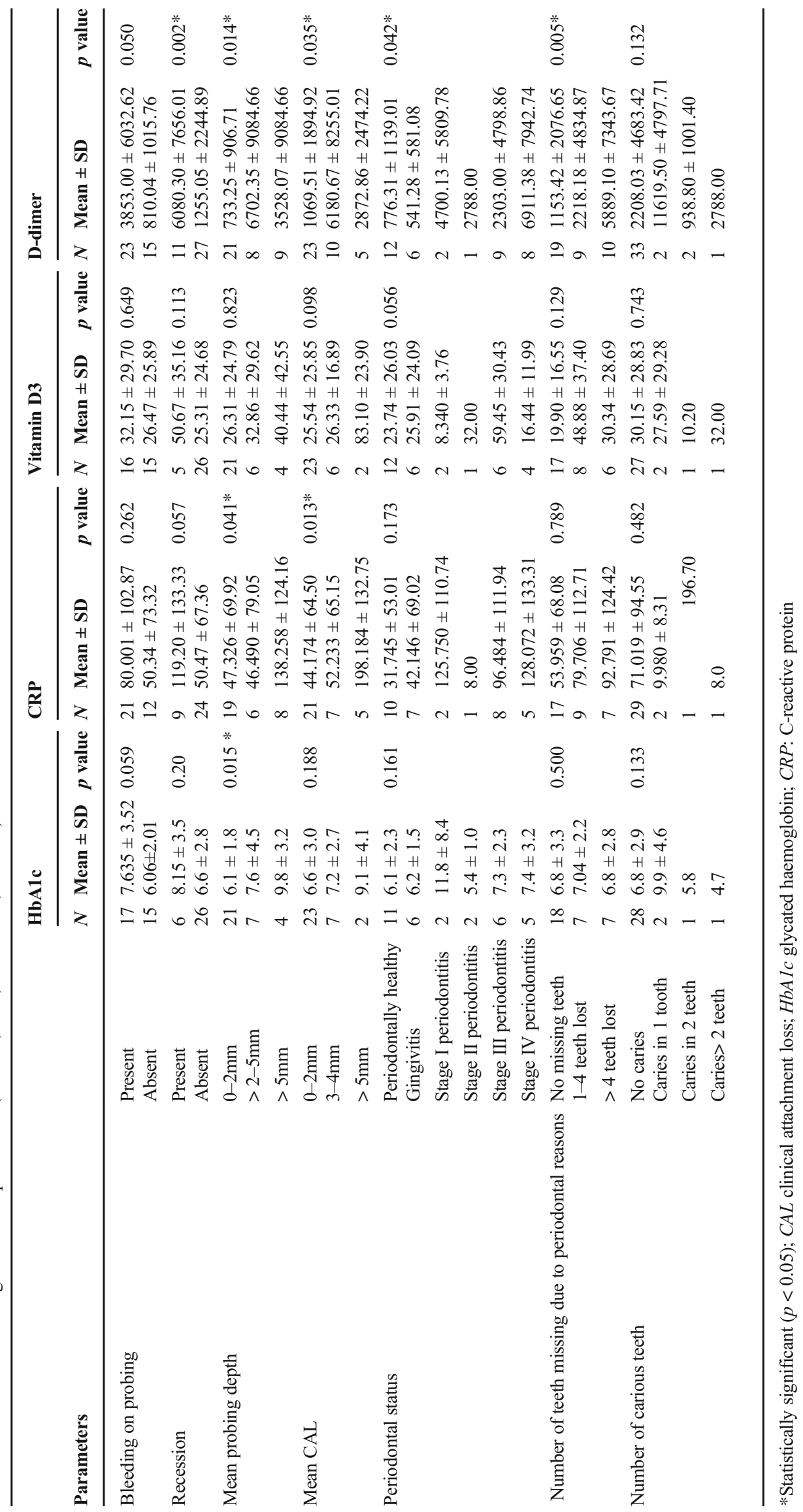




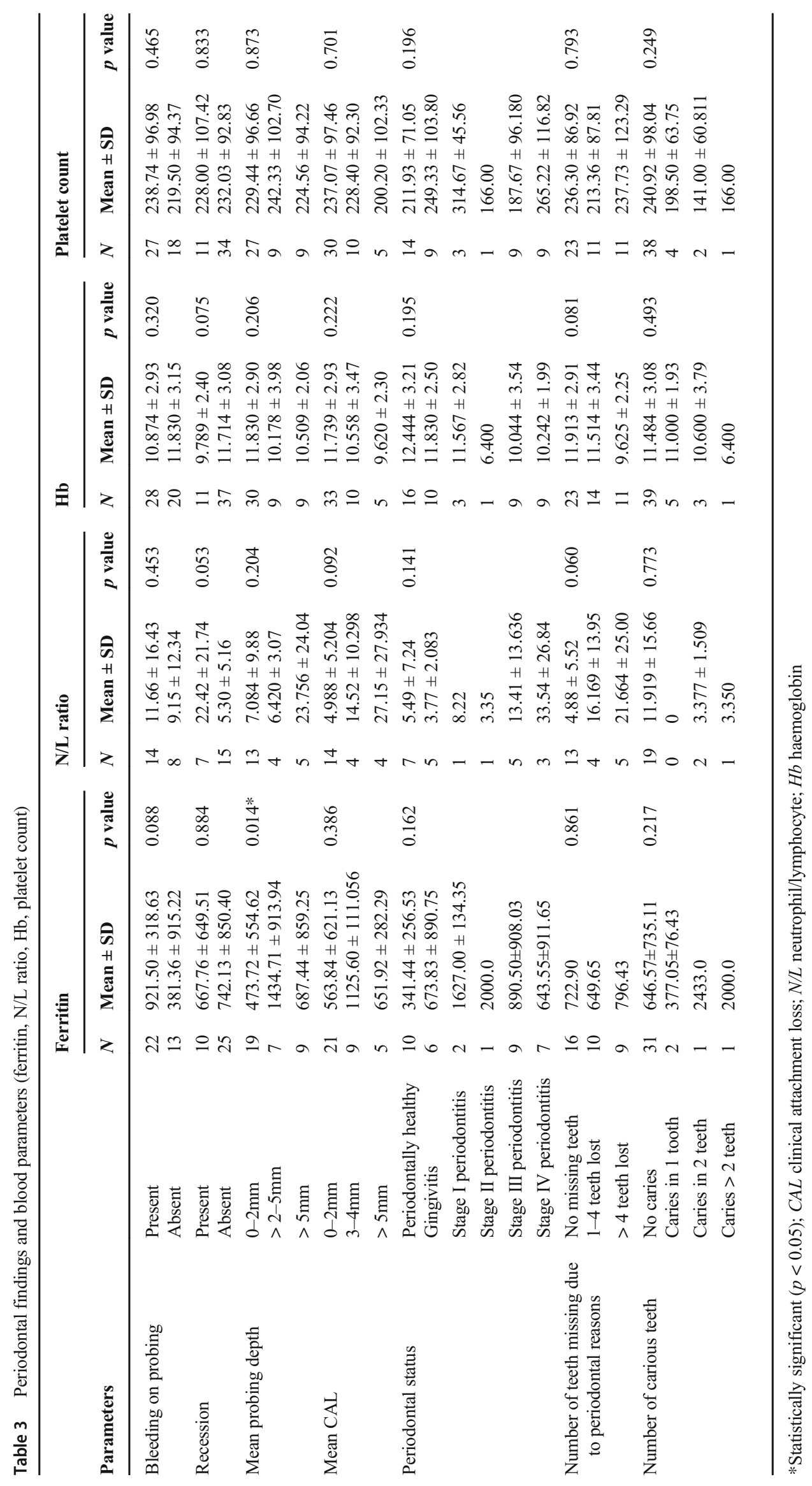




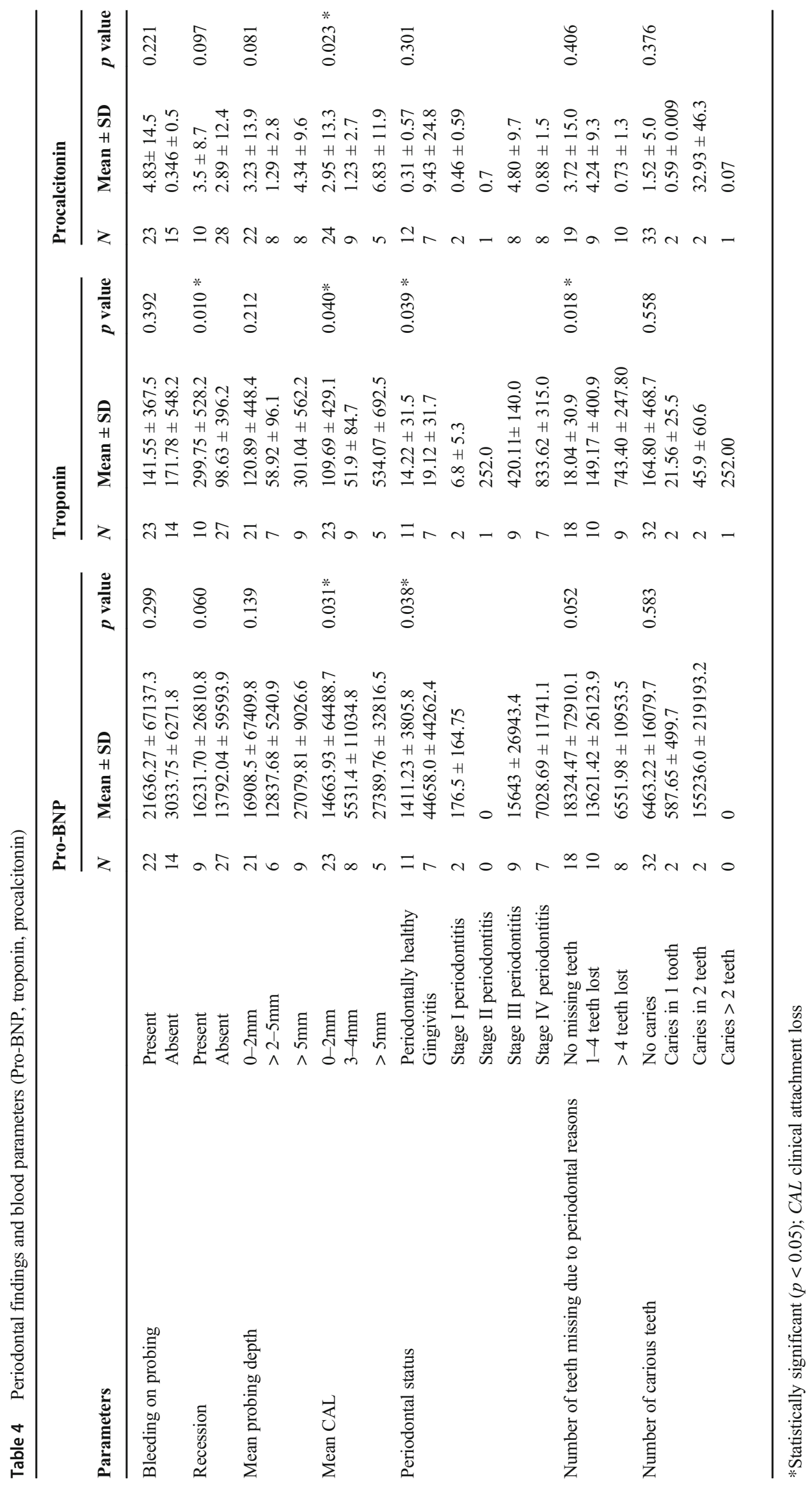




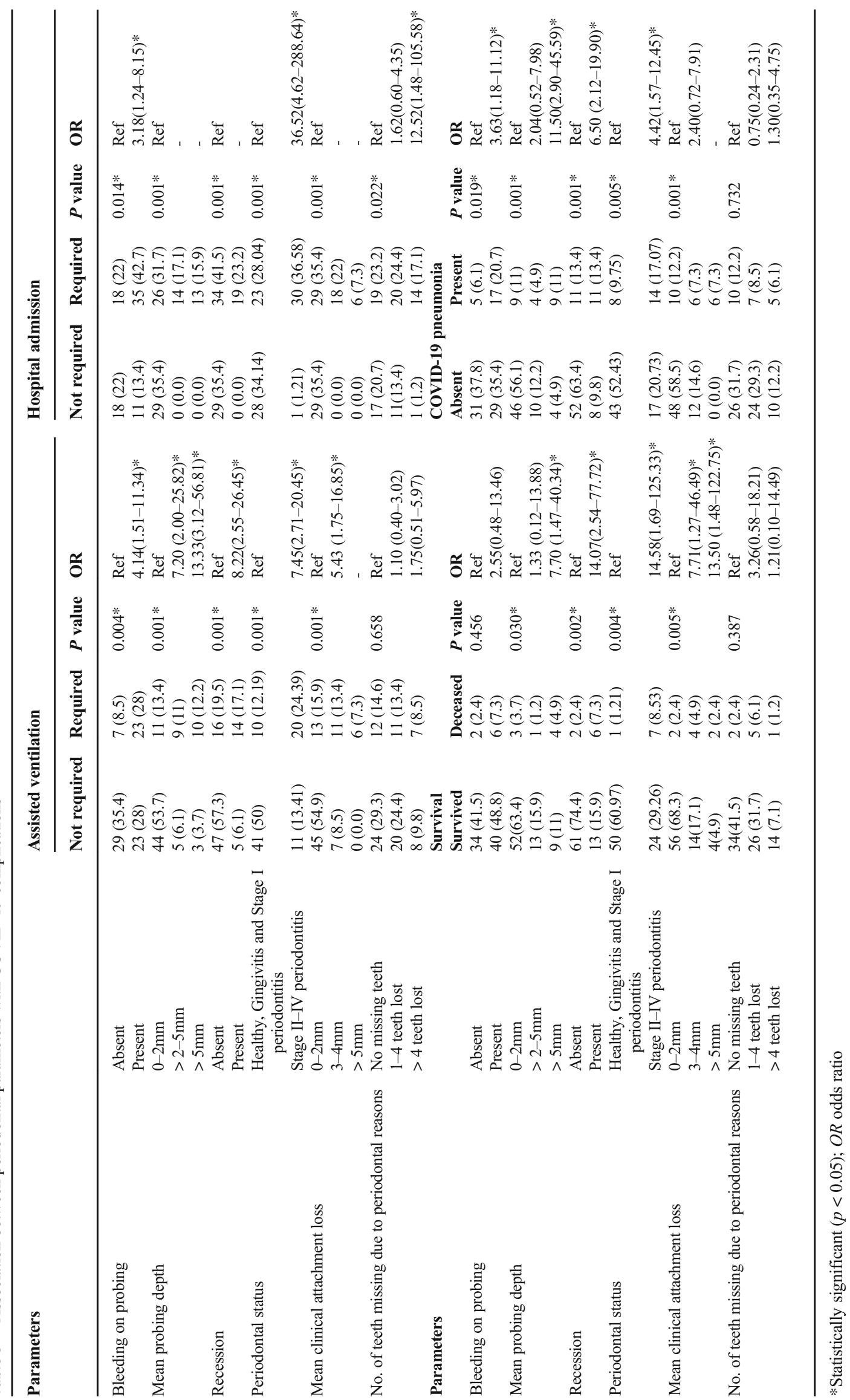




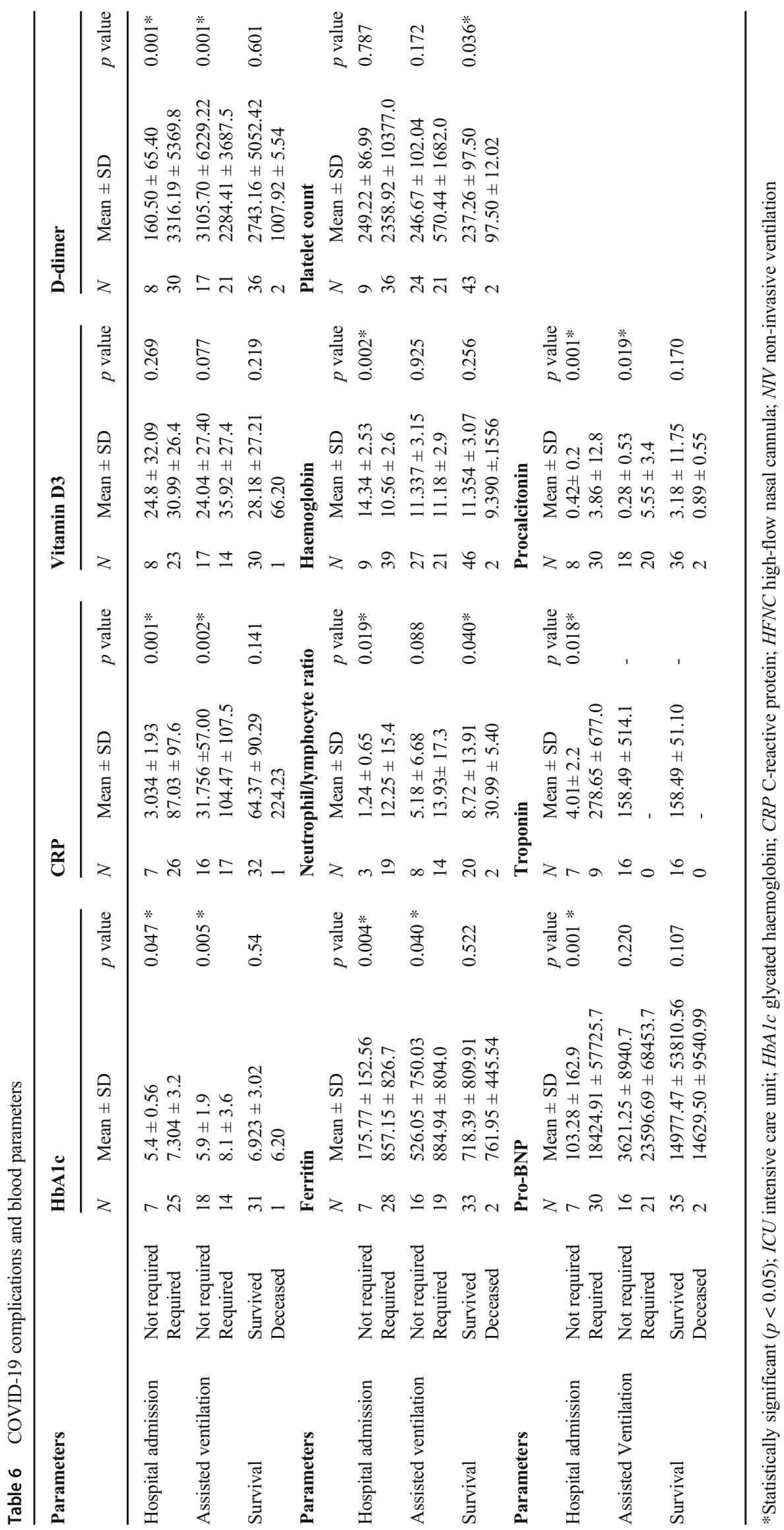


Table 7 aMMP-8 PoC/chairside test results

\begin{tabular}{llll}
\hline & Test result & Periodontally diseased $\mathbf{n}(\boldsymbol{\%})$ & Periodontally healthy $\boldsymbol{n}(\boldsymbol{\%})$ \\
\hline aMMP-8 mouthrinse test & Positive & $29(38.1)$ & $16(21.1)$ \\
& Negative & $20(26.3)$ & $11(14.2)$ \\
\multirow{2}{*}{ aMMP-8 site-specific test } & Positive & $24(33.3)$ & $10(13.9)$ \\
& Negative & $21(29.2)$ & $17(23.6)$ \\
\hline
\end{tabular}

patients suffering from COVID-19 with periodontal disease were more likely to be admitted to a hospital as compared to those who were not.

It is established that a number of comorbidities such as diabetes mellitus, obesity and those affecting the cardiovascular and respiratory systems do play a significant role in determining the prognosis of COVID-19 [26]. At the same time, it is also well established in literature that periodontal disease has definitive links to these chronic disease processes and is a bonafide part of their overall pathophysiological presentation [27, 28].

Periodontal infections incite events which involve both innate and adaptive host immunity. That periodontitis, despite being a largely chronic disease is a systemic inflammation, is confirmed by the presence of acute-phase reactants as part of the innate immune response. These acute-phase reactants, such as CRP, are pro-inflammatory in nature and develop complement activation along with stimulating tissue healing and neutralising invading pathogens. [29]

CRP levels have been touted as an early biomarker for triaging the severity of COVID-19 infections [30]. The present study found that poorer periodontal outcome measures correlated with increased CRP levels in patients suffering from COVID-19. This increase in CRP levels in relation to periodontal compromise is individually substantiated in literature predating the pandemic [29].

Similarly, elevated D-dimer, ferritin, neutrophil lymphocyte ratio and NT-proBNP have been reported to be prognostic markers associated with deteriorating prognosis in patients afflicted with COVID-19, wherein D-dimer is a cross-linked fibrin considered to be a sensitive marker for venous thromboembolism, ferritin is an indicator of systemic inflammation and NT-proBNP is a marker of reduced left ventricular systolic function [31-35].

Brain natriuretic peptide (BNP) is primarily released from the myocardium of the ventricles in response to stress exerted upon the myocardial walls. Produced as a pro-hormone, BNP, a thirty-two amino acid peptide, is cleaved into two peptides, one of which is the active form and the other, N-terminal-proBNP (NT-pro-BNP), which remains inactive biologically. A longer half-life renders NT-pro-BNP a more viable biomarker of inflammation [36].

Increased levels of serum ferritin, an acute phase reactant, have been detected in inflammation and have been demonstrated to correlate positively with CRP levels as well. The concentration of serum ferritin occurs as a result of tissue leakage of this intracellular protein shell. Serum ferritin differs slightly from its tissue form in that it contains minimal to no levels of iron. Inflammation may render clearance of serum ferritin ineffective or suboptimal which may account for its elevated levels. In the midst of an acute phase response, TNFalpha and IL- 1 beta upregulate the synthesis of ferritin $\mathrm{H}$ - and L-subunits which is reflected as an increase in serum ferritin levels [37].

Another cardiac biomarker, troponin, has been evidenced to be increased significantly in severe forms of COVID-19 [38]. Myocardial infarct size is significantly related to eventual patient outcomes and troponins (cTnI and cTnT) form the gold standard biomarkers for this evaluation. Of the two types, cTnI is considered to possess greater reliability for the purposes of determining survival and risk stratification [39].

Neutrophil lymphocyte ratio (NLR) has been evidenced as a marker for systemic inflammation. Epidemiological studies have revealed that NLR correlated with classical systemic inflammation risk factors such as obesity, smoking, diabetes mellitus, hypercholesterolemia, hypertension and metabolic syndrome. In such a manner then, it is safe to say that NLR may be indicative of the severity of inflammatory disease processes [40].

Serum levels of ferritin, NT-proBNP, neutrophil lymphocyte ratio and troponin have been found to be significantly associated with periodontal disease [36, 38, 39, 41, 42]. This association points towards a commonality between periodontal disease and COVID-19-related adverse outcomes. Our study found that there was a correlation between periodontal compromise and increased levels of these blood parameters in COVID-19 patients.

$\mathrm{HbA} 1 \mathrm{c}$ is regarded as the gold standard in blood glucose estimation along with providing an average value over the past 3 months with high levels being associated with complications in diabetic patients. Inflammatory markers such as CRP and serum ferritin have been found to be positively correlated with levels of HbA1c [43]. It has generally been acknowledged that increased levels of HbA1c are associated with hypercoagulability, low oxygen saturation and inflammation in patients suffering from COVID-19. The overall mortality rate of diabetic COVID-19 patients is also reportedly high [43]. In our 
study, we found high levels of $\mathrm{HbA} 1 \mathrm{c}$ correlating with compromised periodontal outcome measures.

Procalcitonin levels remain within reference ranges in patients suffering from non-complicated forms of COVID-19 infection. However, these values increase in patients with super-added bacterial infection [44]. In our study, we found that periodontal disease correlated significantly with elevated procalcitonin levels. Indeed, there is evidence in literature to support the contribution of periodontal disease in the pathophysiology of respiratory illnesses [45].

It has recently also been hypothesised that the breakdown of the oral immune barrier, as may occur in periodontitis, may lead to the dissemination of the SARS-CoV-2 into systemic circulation via its oral reservoirs in saliva and GCF $[5,46]$. Within the constraints of the sample size utilised in the present study, it would be plausible to argue that, while the results seem indicative of this, a direct causal relationship may not be established between the presence of periodontitis and poorer COVID-19-related outcomes.

It would hence be prudent to state that an indirect link may exist in the form of periodontal disease resulting in chronic systemic compromise which may further cascade into a socalled comorbidity affecting the eventual outcome of COVID19 infection. Periodontal disease would then have both a direct and indirect impact upon COVID-19-related outcomes by virtue of its presence.

The aMMP- 8 mouthrinse and site-specific kits were able to correctly identify periodontal disease in $38.1 \%$ and $33.3 \%$ of patients with periodontal disease, respectively. However, the kits also tested positive for $21.1 \%$ (mouthrinse kit) and $13.9 \%$ (site specific kit) in periodontally healthy subjects. A higher number of false positives were being recorded by the kits on account of the elevated aMMP-8 levels in the oral cavity due to the ensuing cytokine storm associated with COVID-19 wherein various inflammatory cytokines could have led to an upregulation in the expression and degranulation of aMMP-8.

A previous study utilised three self-reported oral health indicators to determine a relationship between the presence of periodontal disease and COVID-19 prognosis and found significant association of the indicators with mortality [19]. The authors, in the current study, found a similar relation in the included cohort.

Seeing as periodontal disease predominantly stems from bacterial interactions with the host, the maintenance of oral hygiene assumes greater importance in the face of this novel entity. However, it would serve the scientific community well to base recommendations on substantiated claims and avoid the temptation of joining certain dots where none may exist. In the same vein, maintenance of oral hygiene does continue to be of importance in the COVID-19 era, not only due to a direct correlation between periodontal compromise and the COVID19 disease process but also due to the indirect systemic effects periodontal disease may have, to eventually determine COVID-19-related prognosis and in the identification of potentially at-risk patient populations.

Most research currently seems to have been concentrated on verifying whether the presence of periodontal disease affects COVID-19-related outcomes. It would, however, be interesting to see whether there exists the possibility of crosstalk between the SARS-CoV-2 and the oral microbiome either directly or in a phage-mediated manner [47, 48].

\section{Limitations}

The study had some limitations and results need to be extrapolated with caution. A causal relationship cannot be established due to the cross-sectional design of the study. Another limitation can be the small sample size. However, this is the first study in literature to conduct intra-oral examination among potentially infectious patients. Further studies are required to validate the result of the present work.

\section{Conclusion}

There is a direct association between periodontal disease and COVID-19-related outcomes. However, as periodontal disease is both reflective and deterministic of systemic health, it might also play an indirect role in worsening the status of comorbidities more directly associated with a poorer prognosis of COVID-19-related adverse outcomes.

Authors' contribution S.G. contributed to the conception, design, data acquisition, analysis and interpretation; drafted the manuscript; and critically revised the manuscript. R.M. contributed to the conception and design, acquisition, analysis and interpretation and critically revised the manuscript. M.S. contributed to the acquisition and critically revised the manuscript. S.K. contributed to the acquisition and critically revised the manuscript. V.S. contributed to the analysis and interpretation and drafted the manuscript. P.K. contributed to the analysis and interpretation and critically revised the manuscript. R.K.S. contributed to the acquisition and critically revised the manuscript. A.K. contributed to the analysis and interpretation and drafted the manuscript. Kr.G. contributed to the analysis and interpretation and critically revised the manuscript. Ka.G contributed to the analysis and interpretation and critically revised the manuscript. M.P.S. contributed to the analysis and interpretation and critically revised the manuscript. K.K. contributed to the analysis and interpretation and critically revised the manuscript. V.M. contributed to the analysis and interpretation and critically revised the manuscript. A.B. contributed to the analysis and interpretation and critically revised the manuscript. T.S. contributed to the analysis and interpretation and critically revised the manuscript. I.R. contributed to the analysis and interpretation and critically revised the manuscript. All authors gave final approval and agree both to be personally accountable for the authors' own contributions and to ensure that questions related to the accuracy or integrity of any part of the work, even ones in which the authors were not personally involved are appropriately investigated, resolved and the resolution documented in the literature. 


\section{Declarations}

Ethical approval All procedures performed in studies involving human participants were in accordance with the ethical standards of the institutional research committee and with the 1964 Helsinki Declaration and its later amendments or comparable ethical standards.

Informed consent Informed consent was obtained from all individual participants included in the study.

Consent for publication The authors confirm that they have obtained consent from the study participants to publish the data.

Conflict of Interest T. Sorsa is the inventor of US-patents 5652223, 5736341, 5866432, 6143476, 2017/0023571A1 (granted 6.6.2019), WO2018/060553A1 (granted 31.5.2018), 10488415B2, and a Japanese patent 2016-554676.

The authors declare that they have no conflict of interest.

\section{References}

1. Gomes-Filho IS, Cruz SSD, Trindade SC, Passos-Soares JS, Carvalho-Filho PC, Figueiredo ACMG, Lyrio AO, Hintz AM, Pereira MG, Scannapieco F (2020) Periodontitis and respiratory diseases: a systematic review with meta-analysis. Oral Dis 26(2): 439-446. https://doi.org/10.1111/odi.13228

2. Sampson V, Kamona N, Sampson A (2020) Could there be a link between oral hygiene and the severity of SARS-CoV-2 infections? Br Dent J 228(12):971-975. https://doi.org/10.1038/s41415-020$1747-8$

3. Sahni V, Gupta S (2020) COVID-19 \& Periodontitis: the cytokine connection. Med Hypotheses 144:109908. https://doi.org/10.1016/ j.mehy.2020.109908

4. Badran Z, Gaudin A, Struillou X, Amador G, Soueidan A (2020) Periodontal pockets: a potential reservoir for SARS-CoV-2? Med Hypotheses 143:109907. https://doi.org/10.1016/j.mehy.2020. 109907

5. Gupta S, Mohindra R, Chauhan PK, Singla V, Goyal K, Sahni V, Gaur R, Verma DK, Ghosh A, Soni RK, Suri V, Bhalla A, Singh MP (2021) SARS-CoV-2 Detection in Gingival Crevicular Fluid. J Dent Res 100(2):187-193. https://doi.org/10.1177/ 0022034520970536

6. Malek AE, Granwehr BP, Kontoyiannis DP (2020) Doxycycline as a potential partner of COVID-19 therapies. IDCases. 21:e00864. https://doi.org/10.1016/j.idcr.2020.e00864

7. Kong WH, Li Y, Peng MW, Kong DG, Yang XB, Wang L, Liu MQ (2020) SARS-CoV-2 detection in patients with influenza-like illness. Nat Microbiol 5(5):675-678. https://doi.org/10.1038/ s41564-020-0713-1

8. Yates PA, Newman SA, Oshry LJ, Glassman RH, Leone AM, Reichel E (2020) Doxycycline treatment of high-risk COVID-19positive patients with comorbid pulmonary disease. Ther Adv Respir Dis 14:1753466620951053. https://doi.org/10.1177/ 1753466620951053

9. Ding Y, Uitto VJ, Haapasalo M, Lounatmaa K, Konttinen YT, Salo T, Grenier D, Sorsa T (1996) Membrane components of Treponema denticola trigger proteinase release from human polymorphonuclear leukocytes. J Dent Res 75(12):1986-1993. https://doi.org/10. $1177 / 00220345960750121101$

10. Sorsa T, Tjäderhane L, Konttinen YT, Lauhio A, Salo T, Lee HM, Golub LM, Brown DL, Mäntylä P (2006) Matrix metalloproteinases: contribution to pathogenesis, diagnosis and treatment of periodontal inflammation. Ann Med 38(5):306-321. https://doi. org/10.1080/07853890600800103

11. Sorsa T, Alassiri S, Grigoriadis A, Räisänen IT, Pärnänen P, Nwhator SO, Gieselmann DR, Sakellari D (2020) Active MMP-8 (aMMP-8) as a grading and staging biomarker in the periodontitis classification. Diagnostics (Basel) 10(2):61. https://doi.org/10. 3390/diagnostics10020061

12. Räisänen IT, Sorsa T, van der Schoor GJ, Tervahartiala $T$, van der Schoor P, Gieselmann DR, Heikkinen AM (2019) Active matrix metalloproteinase- 8 point-of-care (PoC)/chairside mouthrinse test vs. bleeding on probing in diagnosing subclinical periodontitis in adolescents. Diagnostics (Basel) 9(1):34. https://doi.org/10.3390/ diagnostics9010034

13. Keskin M, Lähteenmäki H, Rathnayake N, Räisänen IT, Tervahartiala T, Pärnänen P, Șenışık AM, Karaçetin D, Yentek Balkanay A, Heikkilä P, Hagström J, Rautava J, Haglund C, Gursoy UK, Silbereisen A, Bostanci N, Sorsa T (2020) Active matrix metalloproteinase- 8 and interleukin- 6 detect periodontal degeneration caused by radiotherapy of head and neck cancer: a pilot study. Expert Rev Proteomics 17(10):777-784. https://doi.org/10. 1080/14789450.2020.1858056

14. Lähteenmäki H, Umeizudike KA, Heikkinen AM, Räisänen IT, Rathnayake N, Johannsen G, Tervahartiala T, Nwhator SO, Sorsa T (2020) aMMP-8 Point-of-care/chairside oral fluid technology as a rapid, non-invasive tool for periodontitis and peri-implantitis screening in a medical care setting. Diagnostics (Basel) 10(8):562. https://doi.org/10.3390/diagnostics10080562

15. Sorsa T, Gursoy UK, Nwhator S, Hernandez M, Tervahartiala T, Leppilahti J, Gursoy M, Könönen E, Emingil G, Pussinen PJ, Mäntylä P (2016) Analysis of matrix metalloproteinases, especially MMP-8, in gingival creviclular fluid, mouthrinse and saliva for monitoring periodontal diseases. Periodontol 70(1):142-163. https://doi.org/10.1111/prd.12101

16. Sorsa T, Gieselmann D, Arweiler NB, Hernández M (2017) A quantitative point-of-care test for periodontal and dental periimplant diseases. Nat Rev Dis Primers 3:17069. https://doi.org/10. 1038/nrdp.2017.69

17. Gupta S, Sahni V (2020) The intriguing commonality of NETosis between COVID-19 \& Periodontal disease. Med Hypotheses 144: 109968. https://doi.org/10.1016/j.mehy.2020.109968

18. Räisänen IT, Umeizudike KA, Pärnänen P, Heikkilä P, Tervahartiala T, Nwhator SO, Grigoriadis A, Sakellari D, Sorsa T (2020) Periodontal disease and targeted prevention using aMMP-8 point-of-care oral fluid analytics in the COVID-19 era. Med Hypotheses 144:110276. https://doi.org/10.1016/j.mehy.2020. 110276

19. Larvin H, Wilmott S, Wu J, Kang J (2020) The impact of periodontal disease on hospital admission and mortality during COVID-19 pandemic. Front Med (Lausanne) 7:604980. https://doi.org/10. 3389/fmed.2020.604980

20. Marouf N, Cai W, Said KN, Daas H, Diab H, Chinta VR, Hssain AA, Nicolau B, Sanz M, Tamimi F (2021) Association between periodontitis and severity of COVID-19 infection: A case-control study. J Clin Periodontol 48(4):483-491. https://doi.org/10.1111/ jcpe. 13435

21. Chapple ILC, Mealey BL, Van Dyke TE, Bartold PM, Dommisch $\mathrm{H}$, Eickholz P, Geisinger ML, Genco RJ, Glogauer M, Goldstein M, Griffin TJ, Holmstrup P, Johnson GK, Kapila Y, Lang NP, Meyle J, Murakami S, Plemons J, Romito GA, Shapira L, Tatakis DN, Teughels W, Trombelli L, Walter C, Wimmer G, Xenoudi P, Yoshie H (2018) Periodontal health and gingival diseases and conditions on an intact and a reduced periodontium: consensus report of workgroup 1 of the 2017 World Workshop on the Classification of Periodontal and Peri-Implant Diseases and Conditions. J Periodontol 89(Suppl 1):S74-S84. https://doi.org/10.1002/JPER. 17-0719 
22. Trombelli L, Farina R, Silva CO, Tatakis DN (2018) Plaqueinduced gingivitis: case definition and diagnostic considerations. J Clin Periodontol 45(Suppl 20):S44-S67. https://doi.org/10.1111/ jcpe.12939

23. Tonetti MS, Greenwell H, Kornman KS (2018) Staging and grading of periodontitis: Framework and proposal of a new classification and case definition. J Periodontol 89(Suppl 1):S159-S172. https://doi.org/10.1002/JPER.18-0006 Erratum in: J Periodontol. 2018 Dec;89(12):1475

24. Xie J, Tong Z, Guan X, Du B, Qiu H, Slutsky AS (2020) Critical care crisis and some recommendations during the COVID-19 epidemic in China. Intensive Care Med 46(5):837-840. https://doi.org/ 10.1007/s00134-020-05979-7

25. Ayaz A, Arshad A, Malik H, Ali H, Hussain E, Jamil B (2020) Risk factors for intensive care unit admission and mortality in hospitalized COVID-19 patients. Acute Crit Care 35(4):249-254. https:// doi.org/10.4266/acc.2020.00381

26. Sanyaolu A, Okorie C, Marinkovic A, Patidar R, Younis K, Desai P, Hosein Z, Padda I, Mangat J, Altaf M (2020) Comorbidity and its impact on patients with COVID-19. SN Compr Clin Med 2:10691076. https://doi.org/10.1007/s42399-020-00363-4

27. Mealey BL, Ocampo GL (2007) Diabetes mellitus and periodontal disease. Periodontol 2000 44:127-153. https://doi.org/10.1111/j. 1600-0757.2006.00193.x

28. Paquette DW, Brodala N, Nichols TC (2007) Cardiovascular disease, inflammation, and periodontal infection. Periodontol 2000 44: 113-126. https://doi.org/10.1111/j.1600-0757.2006.00196.x

29. Paraskevas S, Huizinga JD, Loos BG (2008) A systematic review and meta-analyses on C-reactive protein in relation to periodontitis. J Clin Periodontol 35(4):277-290. https://doi.org/10.1111/j.1600051X.2007.01173.x

30. Chen W, Zheng KI, Liu S, Yan Z, Xu C, Qiao Z (2020) Plasma CRP level is positively associated with the severity of COVID-19. Ann Clin Microbiol Antimicrob 19(1):18. https://doi.org/10.1186/ s12941-020-00362-2

31. Düz ME, Balcı A, Menekșe E (2020) D-dimer levels and COVID19 severity: systematic review and meta-analysis. D-dimer seviyeleri ve COVID-19 şiddeti: Sistematik Derleme ve Metaanaliz. Tuberkuloz ve toraks 68(4):353-360. https://doi.org/10. 5578/tt.70351

32. Gao L, Jiang D, Wen XS, Cheng XC, Sun M, He B, You LN, Lei P, Tan XW, Qin S, Cai GQ, Zhang DY (2020) Prognostic value of NT-proBNP in patients with severe COVID-19. Respir Res 21(1): 83. https://doi.org/10.1186/s12931-020-01352-w

33. Cheng L, Li H, Li L, Liu C, Yan S, Chen H, Li Y (2020) Ferritin in the coronavirus disease 2019 (COVID-19): a systematic review and meta-analysis. J Clin Lab Anal 34(10):e23618. https://doi.org/10. $1002 /$ jcla.23618

34. Pranata R, Huang I, Lukito AA, Raharjo SB (2020) Elevated Nterminal pro-brain natriuretic peptide is associated with increased mortality in patients with COVID-19: systematic review and metaanalysis. Postgrad Med J 96(1137):387-391. https://doi.org/10. 1136/postgradmedj-2020-137884
35. Lagunas-Rangel FA (2020) Neutrophil-to-lymphocyte ratio and lymphocyte-to-C-reactive protein ratio in patients with severe coronavirus disease 2019 (COVID-19): a meta-analysis. J Med Virol 92(10):1733-1734. https://doi.org/10.1002/jmv.25819

36. Leira Y, Blanco J (2018) Brain natriuretic peptide serum levels in periodontitis. J Periodontal Res 53(4):575-581

37. Kalantar-Zadeh K, Rodriguez RA, Humphreys MH (2004) Association between serum ferritin and measures of inflammation, nutrition and iron in haemodialysis patients. Nephrol Dial Transplant 19(1):141-149. https://doi.org/10.1093/ndt/gfg493

38. Lippi G, Lavie CJ, Sanchis-Gomar F (2020) Cardiac troponin I in patients with coronavirus disease 2019 (COVID-19): evidence from a meta-analysis. Prog Cardiovasc Dis 63(3):390-391. https://doi. org/10.1016/j.pcad.2020.03.001

39. Marfil-Alvarez R, Mesa F, Arrebola-Moreno A, RamirezHernandez JA, Magan-Fernandez A, O’Valle F, Galindo-Moreno P, Catena A (2014) Acute myocardial infarct size is related to periodontitis extent and severity. J Dent Res 93(10):993-998

40. Balta S, Ozturk C, Balta I, Demirkol S, Demir M, Celik T, Iyisoy A (2016) The Neutrophil-Lymphocyte Ratio and Inflammation. Angiology. 67(3):298-299. https://doi.org/10.1177/ 0003319715615252

41. Chakraborty S, Tewari S, Sharma RK, Narula SC (2014) Effect of non-surgical periodontal therapy on serum ferritin levels: an interventional study. J Periodontol 85(5):688-696

42. Lu R, Li W, Wang X, Shi D, Meng H (2020) Elevated neutrophilto-lymphocyte ratio but not platelet-to-lymphocyte ratio is associated with generalised aggressive periodontitis in a Chinese population. J Periodontol 92:507-513

43. Wang Z, Du Z, Zhu F (2020) Glycosylated hemoglobin is associated with systemic inflammation, hypercoagulability, and prognosis of COVID-19 patients. Diabetes Res Clin Pract 164:108214. https://doi.org/10.1016/j.diabres.2020.108214

44. Lippi G, Plebani M (2020) Procalcitonin in patients with severe coronavirus disease 2019 (COVID-19): A meta-analysis. Clin Chim Acta 505:190-191. https://doi.org/10.1016/j.cca.2020.03. 004

45. Slots J (2010) Herpesviral-bacterial interactions in periodontal diseases. Periodontol 52(1):117-140. https://doi.org/10.1111/j.16000757.2009.00308.x

46. Lloyd-Jones G, Molayem S, Pontes CC, Chapple I (2021) The COVID-19 pathway: a proposed oral-vascular-pulmonary route of SARS-CoV-2 infection and the importance of oral healthcare measures. J Oral Med Dent Res 2(1):1-25

47. Szafrański SP, Slots J, Stiesch M (2000) The human oral phageome (2021). Periodontol 86(1):79-96. https://doi.org/10.1111/prd. 12363

48. Diaz PI (2021) Subgingival fungi, Archaea, and viruses under the omics loupe. Periodontol 85(1):82-89. https://doi.org/10.1111/prd. 12352

Publisher's note Springer Nature remains neutral with regard to jurisdictional claims in published maps and institutional affiliations. 